\title{
A Chinese Empire in the Making? Questioning Myths from the Agri-Food Sector in Chana
}

\section{Jixia Lu}

While China's expanding presence in Africa is often framed as a new project in empire building, the Chinese authorities explain their engagement on the continent as simple 'SouthSouth cooperation'. Taking the agricultural sector in Ghana as a case study, this article challenges both narratives and argues that Chinese farmers in Africa are not a 'silent army' (either malevolent or benevolent), but instead are largely precarious individuals attempting to meet their livelihood needs.
Western media and research often frame China's expanding presence in African countries as a new project in empire building on the continent. The Chinese government, on the contrary, espouses a very different narrative-one which depicts Chinese companies and migrants as promoting development through beneficial South-South cooperation resulting in mechanisation and advanced techniques. In this way, in both academic research and popular discourse, discussions about China's developmental role in contemporary Africa often end up implicitly categorising all the activities of Chinese businesses and individual migrants in African countries as being either malevolent or benevolent extensions of China's expanding global influence.

This is particularly apparent in the agricultural sector. At present, most

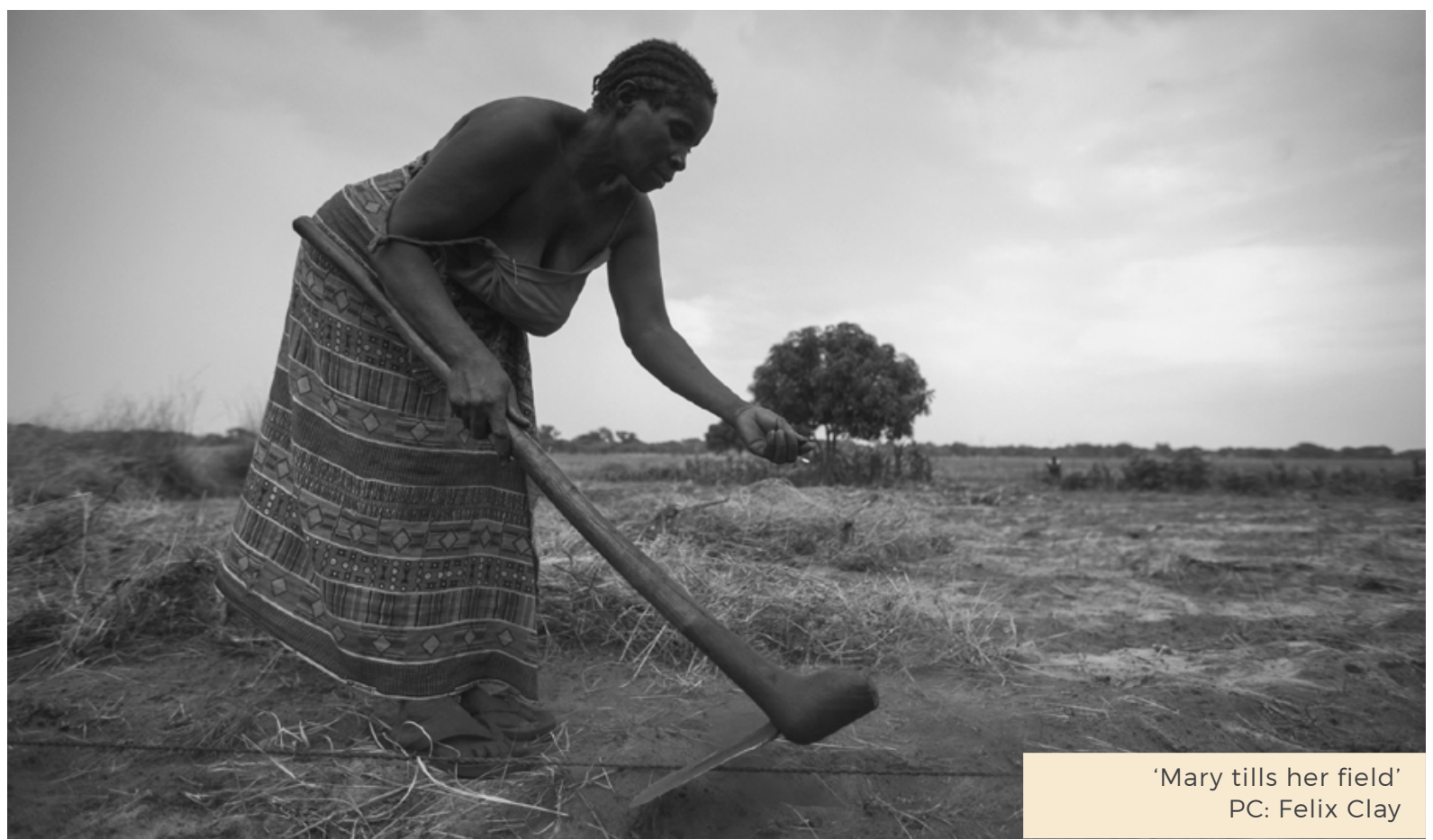


media attention and research on Chinese agricultural engagements in Africa focus on aid or commercial investments by large stateowned enterprises (SOEs), neglecting the fact that on the African continent there is also a growing number of small-scale farms run by individual Chinese migrants and their families. Indeed, while doing fieldwork in Ghana (Cook et al. 2016), I only encountered one case of large-scale Chinese agricultural investment that involved modern mechanised technologies aiming to produce rice for the local Ghanaian market. I did, however, encounter a collection of small-scale Chinese farms that are filling a very different niche. They are characterised by strong personal networks and family relations, and target an expatriate population trying to make ends meet. Such endeavours do not fit neatly into the narratives espoused neither by the Chinese government nor Western media and research

In this article, I will take Ghana as a case study to explore how Chinese migrants operate in the agri-food sector in Africa. In particular, I will argue that Chinese farmers in Africa are not a 'silent army' (either malevolent or benevolent), but are instead largely precarious individuals attempting to meet their livelihood needs. Moreover, these migrants are a symptom of, and a response to, wider global migration dynamics. In particular, many of these small-scale farmers have gone into Ghanaian agriculture in order to provide for the huge influx of Chinese migrant miners (see Loubere and Crawford in this issue). In this way, Chinese farmers in Ghana can be considered reflective of wider processes of contemporary globalisation.

\section{Chinese Migration to Ghana}

Although since the Mao era there have been groups of Chinese people dwelling in Ghana-many of whom had originally come over as aid experts-the last few years have seen a dramatic increase in the number of Chinese immigrants in the country. This is primarily due to the small-scale mining phenomenon and the fact that Chinese companies have entered a growing number of sectors, including mining, construction, and manufacturing, just to name a few. In addition, Chinese migrants maintain a significance presence in retail trade, fishing, small-scale mining, and timber sectors, much of it outside the law and without proper registration. It is, therefore, not surprising that data on the number of Chinese migrants in Ghana are limited and unreliable, with estimates varying between seven and twenty thousand (Mohan et al. 2014). Still, even these figures may be conservative if we consider that in August 2013 the South China Morning Post quoted the secretary general of the Chinese Mining Association in Ghana as saying that more than fifty thousand Chinese gold miners had poured into the country since 2005 ( $\mathrm{He}$ 2013). Another article from The Guardian published roughly at the same time reported that 4,592 illegal Chinese gold miners had been deported from June to July 2013 alone (Hirsch 2013).

While Chinese miners in Ghana have often featured in the international media, China and Ghana have a longer history of engagement in agriculture than in mining. Cooperation in agriculture between China and Ghana goes back to the 1960s, and has continued to grow and develop over subsequent decades (Amanor and Chichav 2016). Today, China and Ghana officially cooperate in a number of sectors, including agro-processing, irrigation, infrastructure development, and agricultural technology (Amanor 2013). Chinese agronomists even teach at the University of Ghana. Yet, just as the information on Chinese migration is patchy and unreliable, data on Chinese investment in the agricultural sector are incomplete and often inaccurate. According to some estimates, Chinese investments in agriculture constitute about four per cent of 
total Chinese investments in the country, with the largest being in rice irrigation projects (Amanor 2015). In other words, compared with other industries, farming seems to be a relatively neglected sector for the Chinese in Ghana.

It is clear from our fieldwork that in Ghana there are only a few formally registered farms. According to a list provided by the Ghana Investment Promotion Centre, only twelve Chinese farms officially registered with the government between 1994 and 2013. Moreover, after attempting to get in touch with these farms, we found that only two of them were actually contactable. Both were registered as producing vegetables and one was said to rear pigs. However, while we were visiting the official farms we had contacted, we by chance met some other unlisted farms owned by Chinese individuals, as well as some unregistered farms owned by large Chinese SOEs with their own small vegetable and pig farms geared towards meeting their own consumption purposes, i.e. for their employees. To shed some light on why Chinese people migrate to Ghana to undertake smallscale agriculture I will discuss three of these small-scale individually-owned farms, two of them registered and one not. The three farms were between two and twenty hectares and, on average, they employed three Chinese nationals as managers and technicians and five to ten local people as manual workers.

\section{Profiling Chinese Farmers in Ghana}

According to our findings, many Chinese small-scale farmers in Ghana come from non-agricultural backgrounds. In the cases examined in this article, all three farm owners were from different provinces in southern China (Hunan, Guangdong, and Zhejiang), but only one of them migrated specifically for agriculture. Before setting up his farm, the owner of one of the farms had been trading agricultural products between China and Ghana. Another of the farm owners had been working in Ghana as an engineer in a Chinese company. Only the owner of the third farm came to Ghana specifically to set up a farm. However, his migration history was far more complex than those of the other people we met. For the past two decades he had been living and farming on the Northern Mariana Islands, a US Commonwealth territory in the middle of the Pacific Ocean where he had moved during the Cultural Revolution.

Despite their very varied backgrounds, though, all of them have learned about farming, livestock, agricultural management, and marketing in a remarkably challenging social, linguistic, and physical environment. Furthermore, they also have shown a willingness to convert to a new line of business if it proves to be more economically viable. Moreover, their motivations to start their farms were somewhat similar: all of them said they aimed to meet their own needs for vegetable consumption in the first instance. As a Chinese employee on one of the farms put it: 'The boss of our farm is about sixty years old. He was running a trade business in agricultural products between China and Ghana four years ago. Later on, when he found it difficult to find Chinese vegetables in the local market, though, he started his first farm.' In this way, the farm was established as a response to a particular market need, which itself arose due to the wider processes of global migration.

The Chinese farmers we interviewed stated that in order to successfully run a small farm in Ghana, they had to consider the following elements: land, water resources, access to markets, and labour. Among these aspects, land was the most significant and challenging element to consider. Generally speaking, the Chinese farmers had great difficulties securing the land of the size and quality they wanted within the existing legal framework. Part of the problem is that throughout Ghana there is a lack of clarity about land ownership, 
particularly between local chiefs and local governments. This is a major hindrance for those foreigners who want to invest in agricultural activities in Africa, because it is not always clear who owns the land rights. This meant that the Chinese farmers were often unable to operate in a technically 'legal' way, not necessarily because they are maliciously land-grabbing or exploiting local people, but rather because legality in this context is tenuous for everyone involved. For this reason, many Chinese migrants give up farming after one or two years.

That being said, although in the beginning the farms we examined encountered a lot of difficulties, those who stayed and persisted in earlier years were able to survive due to a sizeable Chinese community that provided a ready market, particularly the rapid influx of illegal miners after the increase in gold prices in 2008 (see the chapter by Loubere and Crawford on pp. 116-121 in the present book). However, due to the expulsion of a large number of Chinese gold miners in June 2013, the farms lost a significant portion of their market. The remaining Chinese farmers confirmed that they have been selling less than before and are, therefore, struggling. Besides the difficulties mentioned above, since their products are sold locally, they still need to compete in the local market, both among themselves and with Ghanaian farmers. This greatly tests the farmers' business acumen, patience, and resilience.

\section{Dispelling the Misconceptions}

The examples provided above suggest that Chinese 'land grabs' and agricultural 'cooperation' in Ghana in fact mostly consists of informal small plots of a few hectares producing vegetables to sell locally. While there are a handful of larger SOE farms, they are primarily operating for the consumption needs of the personnel employed by the company. More widespread are small individually-owned farms; however, the majority of these farmers are working hard to meet their own livelihood needs in an increasingly unpredictable and volatile market. This does not fit neatly into the western media discourses focussed on land grabbing and neo-imperialism, nor into the narrative of the Chinese government centred on the idea of mutually beneficial SouthSouth cooperation.

From this perspective, Chinese agricultural workers in Africa are not an organised 'silent army' of labourers, but are actually diverse and fragmented. They are relatively marginal people moving from one place to another in an attempt to improve their livelihoods. Living independently with no support or even contact with the Chinese government, they struggle to ensure their survival in the local markets, facing the competition of local producers and sellers, and surviving in unstable and unclear legal situations. Quite clearly, there is no real prospect for these farms to become large-scale, highly mechanised or capital intensive, which is actually what most African governments yearn for in order to increase agricultural production. In other words, China's presence in the agricultural sector in Africa mostly remains in the realm of individual entrepreneurship, a far cry from the ambition of empire.

\section{Jixia Lu}

Jixia $\mathrm{Lu}$ is an Associate Professor at the College of Humanities and Development Studies, China Agricultural University. Her research fields include Chinese and international development, environment, health and development, development intervention and social change. 
This text is taken from Disturbances in Heaven: A Year of Chinese Labour, Civil Society, and Rights, Made in China Yearbook 2016, edited by Ivan Franceschini, Kevin Lin and Nicholas Loubere, published 2017 by ANU Press, The Australian National University, Canberra, Australia. 